\title{
A Comparative Study of Predictors of Health Service Utilization among Rural and Urban Areas in Ilorin East Local Government Area of Kwara State
}

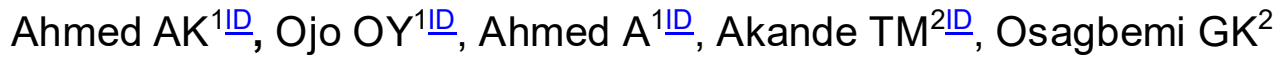

${ }^{1}$ Department of Community Medicine and Primary Care, Federal Medical Centre, Idi-Aba, Abeokuta. Ogun State. Nigeria

${ }^{2}$ Department of Epidemiology and Community Health, University of Ilorin Teaching Hospital, Ilorin. Kwara State. Nigeria

ID: Orcid ID

Submitted: $20^{\text {th }}$ July 2021

Accepted: $17^{\text {th }}$ September 2021

Published: $30^{\text {th }}$ December 2021

\begin{abstract}
Objective: Health facilities utilization among Nigerians is affected by access to hospitals and, availability of personnel. This study compared the predictors of health service utilization in rural and urban areas of llorin East Local Government Area of Kwara State.

Method: A cross-sectional study, involving 250 rural and 250 urban respondents selected through multi-stage sampling techniques. Quantitative data were collected using an interviewer-administered questionnaire. Qualitative data collection was done with an FGD guide. Data were analyzed using SPSS version 16. Chi-square, t-test, and z-test were used to test for significance. The level of significance was set at $p<0.05$.

Results: The mean age of urban respondents was $37.1 \pm 7.9$ years and $42.6 \pm 13.7$ years for rural. Utilization among the urban respondents were $71.2 \%$, and $89.2 \%$ among rural $(z$-score $=27.93$; $p$-value $=0.01$ ). Health services factors such as waiting time (Adjusted $O R=1.012 ; p$-value=0.989) were found to be a strong predictor of utilization among urban respondents compared with the availability of drugs (Adjusted OR=1.696; $p$-value $=0.407$ ) and availability of drugs (Adjusted $\mathrm{OR}=1.696$; $p$-value=0.407) which were the strongest predictor among rural respondents, though they were all not statistically significant. Other factors identified were lack of staff $46.5 \%$ among rural and lack of drug $26.1 \%$ among urban communities respectively.

Conclusion: The study demonstrated higher utilization among the rural community. Knowledge of available health services was important for utilization; waiting time, and availability of drugs were major predictors of health service utilization among urban and rural communities respectively.
\end{abstract}

Keywords: Health, Service, utilization, Urban; Rural; Kwara State

\section{Plain English summary}

The study aimed to assess the predictors of healthcare utilization between urban and rural communities in a Local Government Area in Kwara State, North-Central, Nigeria. The study found utilization among the urban respondents to be $71.2 \%$ and $89.2 \%$ among rural. The utilization of services was predicted by the waiting time and availability of drugs among urban respondents, and the availability of drugs was the strongest predictor among rural respondents. We recommend continuous training and retraining of staff on triaging of patients, especially in urban clinics and hospitals where patient's turnout could be overwhelming, 
to ensure quality service delivery. The state and local authorities should reduce drug costs through subsidies and make essential drugs available as the availability of medications in this thought to improve hospital visits.

\section{Background}

The utilization of health care services is fundamental to healthy living, socio-economic and infrastructural development (1). Health care utilization is influenced by certain characteristics including the availability of healthcare facilities (1, 2). Availability has a wide dimension which entails distance, accessibility, awareness, transport, language, cultural barrier, and preference. Others are the cost of health care service, and quality of service provided by health care personnel (3).

The utilization of health care still differs greatly between urban and rural communities due to the availability of basic equipment and the presence of trained medical personnel in the urban area with a relatively low supply of same at the rural community where more than $60 \%$ of the population resides $(4,5)$. The disproportionate utilization between rural and urban communities in Nigeria has resulted in varied morbidity and mortality rates. For instance, the 2018 NDHS results show that the infant mortality rate was 67 deaths per 1,000 live births for the 5 years preceding the survey. The child mortality rate was 69 deaths per 1,000 live births, while the under- 5 mortality rate was 132 deaths per 1,000 live births (6). The under-5 mortality rate is higher in rural areas than in urban areas (157 and 92 deaths per 1,000 live births, respectively) (6).

While $84 \%$ of women in urban areas had supervised delivery by a doctor, nurse, or midwife compared with only $56 \%$ of women in rural areas (7).

Overall progress in health indicators has been slowed down, Nigeria ranks among the countries with the highest maternal mortality ratio. The maternal mortality ratio for the 7 years before the 2018 NDHS is estimated at 512 maternal deaths per 100,000 live births (6). The figures are worse in the rural communities where utilization of modern health facilities is limited and most inhabitants patronize local traditional birth attendants $(8,9)$. The utilization of health facilities among rural and urban communities is greatly affected by the distribution of health facilities and the availability of health care personnel at the facilities. Others are the condition of service, lack of working equipment, lack of infrastructure, and poor communication service and access road have been blamed for these seemingly persistent gaps (10).
It is important to note that private health care providers operate in urban settings where income levels are generally high and clients are perceived to have the ability to pay for service rendered. Conversely, there is poor access to qualified and competent health professionals for people living in rural and deprived areas that bear a great portion of the disease burden (10). High cost of health services have equally been blamed for the seemingly disproportional utilization of health services for instance, as much as $43 \%$ of respondents in a study reported high cost of transportation, cost of medication and service at the health center, and man-hour lost, were obstacles to utilizing health care services both at the rural and urban facilities (11). A study by Fatusi et al (12) on poverty reduction strategy identified that about $40 \%$ of their respondents were living in poverty and close to $27 \%$ live in extreme poverty (12). Most of these population lives in the rural community with limited access to health care service (13).

Health care utilization among rural dwellers is characterized by longer travel times and greater distances to health centers constituting barriers to repeat visits (14). The inadequacies in access to health facilities have reduced the life expectancy of rural inhabitants, urban slum dwellers, and increased infant mortality (15). Although the urban communities have access to health care services in terms of the road network and availability of personnel, the cost of accessing these services is a form of constraint to urban dwellers, especially the less privileged (16).

The need to address the differences in utilization of health care services among rural and urban communities is important to providing equitable health care services and reducing morbidity and mortality. This study "Comparison of predictors of health service utilization among rural and urban areas in llorin East LGA, Kwara State, Northcentral, Nigeria" sought to identify the differential factors that determine healthcare utilization and the predictors of the determinants. This study bridged the information gap on healthcare utilization and its predictors among selected communities in Ilorin East Local Government Area (LGA) of Kwara State.

\section{Methods}

Study design 
This is a cross-sectional study that employed both qualitative and quantitative methods using an interviewer-administered questionnaire and focus group discussions (FGD). It involved comparative assessment of predictors of health service utilization among rural and urban communities in Ilorin East Local Government Area.

\section{Study area}

The study was carried out in Ilorin East Local Government Area of Kwara State. Ilorin East LGA is one of the sixteen (16) LGAs that made up Kwara State (17). The people of the local government are mainly civil servants, farmers, traders, artisans, and organized private sectors $(17,18,19)$. The 2006 national population census puts the population of Ilorin East Local Government at 207,462 (Male 104,801; Female 102,661) (20, 21).

\section{Study population}

The study population consisted of heads of households in the selected communities. Heads of households were used because they have information on health service utilization activities of members of the household and provides financial support for most activities in the household regardless of their gender. The respondents were adults above the age of 18 years who had lived in the community for not less than 18 months, this is believed to be long enough for the respondent to acquit themselves with socio-cultural activities in the community.

\section{Sample size determination}

The minimum sample size for this study was determined using the formula for comparison of two proportions. The sample size for each group i.e., urban and rural communities calculated thus: $n=\frac{\left(Z_{\alpha}+Z_{\beta}\right)^{2} \times\left(P_{1}\left(1-P_{1}\right)+P_{2}\left(1-P_{2}\right)\right)}{d^{2}}(22)$

Where $\mathrm{n}$ was minimum sample size required; $\alpha=$ $5 \% ; \beta=20 \%$ (80\% power was desired); $Z_{\alpha}=$ Standard normal deviate (SND) value for $\alpha$ (alpha) error $=1.96$, and $Z_{\beta}=$ Standard normal deviate (SND) value for $\beta$ (beta) error $=0.84$ (value corresponding to power of $80 \%$ on the zscore table). Also, $\mathrm{P}_{1}=55.1 \%=0.551=$ Proportion of respondents in an urban community who have used the health facility over a onemonth period (14). $P_{2}=33.8 \%=0.338=$ Proportion of respondents in a rural community who have used the health facility over a onemonth period (23). Finally, $d=$ minimum difference to be detected $\left(P_{1}-P_{2}\right)$.
After adjusting for $10 \%$ non-response, the minimum sample size calculated was 91. However, 250 respondents were used for the study population in each of the two communities (rural and urban) respectively. The reason for the expanded sample size was to allow for appropriate analysis such as cross-tabulation; to provide the desired level of accuracy in the estimate of proportion and to allow a validity of significance test and generalizability of the findings.

\section{Sampling techniques}

The study population was selected using a multistage sampling technique. The sample selection was divided into two strata (i.e., rural and urban communities). A sampling of the two strata occurred independently of each other due to the comparative nature of the study. Ilorin East had a good representation of urban and rural communities.

Stage 1: Selection of wards

From the list of rural and urban communities, a simple random sampling technique by balloting (without replacement) was used to select onethird of the wards which translated to two (2) in the rural and two (2) wards in the urban area respectively. One-third was chosen because of limited resources.

Stage 2: Selection of communities/settlements.

From the selected wards two villages were randomly selected out of the list of villages in each ward in the Local Government Area. There were over fifty (50) villages and the selection of two was due to limited financial and human resources.

Proportional allocation was done for each of the selected communities/settlements to determine the number of respondents from each community/settlement depending on the population of the respective community.

This was carried out using the formula:

$=$ Population of community ${ }^{*}$ Sample size (22)

Population of all communities

Thus, proportionally allocated populations for the respective communities/settlements were:

Urban settlements; 1) Okelele (77), 2) Dada (50), 3 ) Karuma (84), and 4) Ojagboro (72). For the rural villages, there were; 1) Oke-Ose (49), 2) IdiIgba (43), 3) Panada (66), and 4) Budo-Oyo (59). Stage 3: Selection of houses

For each community, the houses that made up the community were counted using the existing National Programme on Immunization numbers. The listing of the houses in the community constitutes the sampling frame. A systematic 
sampling technique was employed in selecting the houses that were involved in the study. However, a sampling interval was calculated to determine the mode of selection of the enumerated houses in the respective villages/settlements selected in stage 2 . Therefore, the $\mathrm{n}^{\text {th }}$ value (i.e., Sampling interval) for urban and rural communities were as calculated above with different values due to differences in the population sizes.

Random numbers were allocated to selected houses for easy identification and selection. The first house was selected from the list of generated random numbers. Further selections were conducted following the calculated sampling interval until the sample size was completed.

In houses where there was more than one household, simple random sampling techniques by balloting were used in selecting the head of household to be interviewed. In situations where the head of a selected household cannot be interviewed or declined to be interviewed the next household was visited until an eligible respondent was obtained while maintaining the sampling interval. It is important to note that the head of a household was anyone that the household members recognize as the head and seen as the decision-maker. Households were groups of individuals eating from the same pot, whether related by birth or otherwise (24). The study participants (heads of households) for the focus group discussion (FGD) were selected using the purposive non-random sample selection methodit provides the researcher the power to select suitable participants freely depending on the ability to provide needed information.

\section{Data collection instruments}

The study utilized an interviewer-administered structured questionnaire for quantitative data collection and the qualitative aspect involved an FGD guide tailored along the general and specific objectives of the study. The questionnaire contained questions to obtain information in line with the general and specific objectives of the study.

The questionnaire was divided into section $A$ : which elicited the socio-demographic characteristics of the respondents. Section B: part had questions on the knowledge of respondents on the availability of health care services in their community. Section C: contained questions on the utilization of health services. Section D: Had questions on factors that influence health service utilization.
The FGD guide was subdivided into five sections or thematic areas. An initial opening statement, section A: made up of questions on knowledge of participants on availability of health care services in their areas, section B: client's utilization of services provided by the health personnel; section C: factors that influence clients' utilization of health services provided, at the end of which there were closing questions. The FGDs were made up of two homogenous groups, consisting of male/female were interviewed separately and were members of the selected communities in Ilorin East Local Government Area.

\section{Pre-testing of instrument}

Ten percent $(10 \%)$ of the estimated sample size (for the urban and rural communities) comprising the questionnaire and FGD guide was pre-tested in Alanamu and Odore (about $30 \mathrm{~km}$ and $50 \mathrm{~km}$ from the study area, respectively) in Ilorin West Local Government Area of Kwara State because they had similar socio-demographic characteristics with Ilorin East Local Government Area. After which appropriate corrections were made to the questionnaire to ensure validity. Pretested questionnaires were used to identify problems with the validity of the test instrument and interpretation and analysis of data obtained from it.

\section{Data collection and analysis}

The data analysis was done using SPSS software version 16. A scoring system was used for rating the respondent's knowledge on utilization of health services by awarding ' 1 ' for correct answer and '0'for wrong answer. The knowledge scores were generated giving minimum and maximum obtainable scores of 0 and 9 respectively. A respondent with a score of 0-3 was assessed as having poor knowledge, a score of 4-6 as having fair knowledge, and a score of 6-9 was rated as having good knowledge (24). Dependent variables were summarized using frequencies and percentages and comparisons were done between the rural and urban communities. Test of association was done using chi-square, level of significance set at $\alpha<0.05(5 \%)$. The predictive factor was determined using multiple regression analytic methods. The independent variables entered into the logistic regression model were those that were significant at $5 \%(p<0.05)$ on multivariate analysis.

The FGD consisted of eight (8) participants in each homogenous group, a total of four sessions were conducted (two in the rural community and two sessions in the urban community), and each 
group had one session, which lasted about one and half hours. Research assistants were trained as recorders (using a tape recorder and notetaking) of the session while the Researcher conducted the interview sessions. The line of discussion was tailored towards the general and specific objectives of the study. The sitting arrangement was circular using chairs and/or benches with the interviewer positioned in such a way that he faced the group to ensure eye contact. The essence of the FGDs was explained to the respective groups and their consent was obtained. The tools for the FGD included an FGD guide, a tape recorder, note pads, and a camera. However, consent of the respondents was sought before photographs were taken.

The FGD recorded sessions on tape were transcribed into notes. The transcripts were then processed, coded and interpreted, and summarized using the prose version of reporting method along the thematic areas. A logbook was prepared and used to chart all the responses from the participants

\section{Results}

In table 1, the mean age of the urban respondents was $37.1 \pm 7.9$ years and $42.6 \pm 13.7$ years for rural. Total male participation was $202(40.4 \%)$ out of which rural accounted for $109(53.96 \%)$ and urban 93(46.04\%)) while total female participation was 298(59.6\%). Majority of respondents in both rural $200(80.0 \%)$ and urban $151(60.4 \%)$ were married, monogamy setting was $122(80.8 \%)$ in urban versus $171(76.3 \%)$ in the rural community $(p$-value $=0.01)$. About $203(81.2 \%)$ urban and $241(96.4 \%)$ rural respondents were employed. Almost half of rural respondents $112(46.5 \%)$ were farmers while about two-thirds 124(61.1\%) of urban respondents were traders, this was found to be statistically significant $(p$-value $=0.01)$

Table 1: Socio-demographic variables of rural and urban.

\begin{tabular}{|c|c|c|c|c|c|}
\hline Variables & Urban (\%) & Rural (\%) & $\chi^{2}$ & df & p-value \\
\hline Age Groups (years) & $n=250$ & $n=250$ & & & \\
\hline $20-29$ & $39(15.6)$ & $32(12,8)$ & & & \\
\hline $30-39$ & 99 (39.6) & 78 (31.2) & & & \\
\hline $40-49$ & $90(36.0)$ & $68(27.2)$ & & & \\
\hline $50-59$ & $22(8.8)$ & $45(18.0)$ & & & \\
\hline$\geq 60$ & $0(0)$ & 27 (10.8) & & & \\
\hline Mean \pm S D & $37.1 \pm 7.9$ & $42.6 \pm 13.7$ & & & \\
\hline \multicolumn{6}{|l|}{ Sex } \\
\hline Male & $93(46.04)$ & 109 (53.96) & & & \\
\hline Female & $157(52.68)$ & $141(47.32)$ & & & \\
\hline Marital status & $\mathrm{n}=\mathbf{2 5 0}$ & $\mathrm{n}=\mathbf{2 5 0}$ & & & \\
\hline Single & $99(39.6)$ & $26(10.4)$ & & & \\
\hline Married & $151(60.4)$ & $200(80.0)$ & & & \\
\hline Divorced & $0(0)$ & $15(6.0)$ & & & \\
\hline Widowed & $0(0)$ & $9(3.6)$ & 48.385 & 2 & 0.01 \\
\hline Marriage type & $n=151$ & $\mathrm{n}=223$ & & & \\
\hline Monogamy & $122(80.8)$ & $171(76.3)$ & & & \\
\hline Polygamy & $29(19.2)$ & $52(23.7)$ & 1.048 & 1 & 0.31 \\
\hline Religion & $\mathrm{n}=\mathbf{2 5 0}$ & $\mathrm{n}=\mathbf{2 5 0}$ & & & \\
\hline Islam & $154(61.6)$ & 149 (59.6) & & & \\
\hline Christianity & $96(38.4)$ & $95(38.0)$ & & & \\
\hline Traditional & $0(0)$ & $6(2.4)$ & 0.015 & 2 & 0.91 \\
\hline Employment status & $N=250$ & $N=250$ & & & \\
\hline Employed & $203(81.2)$ & $241(96.4)$ & & & \\
\hline Unemployed & $47(18.8)$ & $9(3.6)$ & 29.038 & 1 & 0.01 \\
\hline Occupation & $n=203$ & $n=248$ & & & \\
\hline Farming & $0(0)$ & $112(45.0)$ & & & \\
\hline Trading & $124(61.1)$ & $72(29.0)$ & & & \\
\hline Civil servant & 77 (37.9) & $32(13.0)$ & & & \\
\hline Artisan & $2(1.0)$ & $32(13.0)$ & 69.124 & 3 & 0.01 \\
\hline
\end{tabular}




\begin{tabular}{lcclll}
\hline $\begin{array}{l}\text { Estimated monthly income } \\
\text { in naira }\end{array}$ & $\mathbf{n = 2 0 7}$ & $\mathbf{n = 2 3 8}$ & & & \\
$<5000$ & $0(0)$ & $23(9.7)$ & & & \\
$5000-14999$ & $48(23.2)$ & $42(17.6)$ & & & \\
$15000-24999$ & $41(19.8)$ & $63(26.5)$ & & & \\
$25000-34999$ & $83(40.1)$ & $40(16.8)$ & & & \\
$35000-44999$ & $22(10.6)$ & $11(4.6)$ & & \\
45000 and above & $13(6.3)$ & $59(24.8)$ & 74.343 & 5 & 0.01 \\
Average income (Naira) & 30,000 & 20,000 & & & \\
\hline
\end{tabular}

From table 2, on sources of information on available services, health workers $131(37.2 \%)$ were the predominant source of information among rural respondents versus relatives of respondents $123(34.9 \%)$ in the urban community $\left(x^{2}=7.356, p\right.$-value $\left.=0.01\right)$. Most of the health facilities were PHCs-rural communities had $211(84.4 \%)$ of the distribution and urban had $138(55.2 \%)$. Others were secondary facilities which constituted $73(14.6 \%)$ of the total number of health facilities in the study communities (rural had 22(8.8\%) and urban 51(20.4)) these distributions were found to be statistically significant ( $p$-value=0.01). When respondents were rated on the knowledge of available health facilities and services provided, most respondents had a fair knowledge rating of 368 $(73.6 \%)$, those with good knowledge were $53(10.6 \%)$ and poor knowledge were $79(15.8 \%)$.

Table 2: Respondents' knowledge on sources of information and available healthcare facilities in urban and rural communities

\begin{tabular}{|c|c|c|c|c|c|}
\hline Variables & Urban (\%) & Rural (\%) & $\chi^{2}$ & Df & p-value \\
\hline Sources of Information & $\mathbf{n}=\mathbf{2 5 9 ^ { * * }}$ & $n=352^{* *}$ & & & \\
\hline Health Workers & $56(21.6)$ & $131(37.2)$ & 17.085 & 1 & 0.01 \\
\hline Relatives & $64(24.7)$ & $123(34.9)$ & 7.356 & 1 & 0.01 \\
\hline Friends & $23(8.9)$ & $54(15.3)$ & 5.655 & 1 & 0.02 \\
\hline Radio & $51(19.7)$ & $15(4.3)$ & 36.869 & 1 & 0.01 \\
\hline Newspaper & $41(15.8)$ & $22(6.3)$ & 14.808 & 1 & 0.01 \\
\hline Television & $24(9.3)$ & $7(2.0)$ & 16.409 & 1 & 0.01 \\
\hline Available Health facilities & $n=250$ & $\mathrm{n}=\mathbf{2 5 0}$ & & & \\
\hline Primary Health Facility & $138(55.2)$ & $211(84.4)$ & & & \\
\hline Secondary Health Facility & $51(20.4)$ & $22(8.8)$ & & & \\
\hline Tertiary Health Facility & $61(24.4)$ & $17(6.8)$ & 25.421 & 2 & 0.01 \\
\hline Knowledge of services provided & $\mathrm{n}=\mathbf{2 5 0}$ & $\mathrm{n}=\mathbf{2 5 0}$ & & & \\
\hline Yes & $197(78.8)$ & $234(93.6)$ & & & \\
\hline No & $53(21.2)$ & $16(6.4)$ & 23.017 & 1 & 0.01 \\
\hline Services provided & $n=261^{* *}$ & $\mathrm{n}=442^{* *}$ & & & \\
\hline Outpatient treatment & $94(36.0)$ & $130(29.4)$ & 1.279 & 1 & 0.21 \\
\hline Delivery & $32(12.3)$ & $112(25.3)$ & 48.194 & 1 & 0.01 \\
\hline Immunization/Family planning services & $68(26.1)$ & $83(18.8)$ & 4.618 & 1 & 0.01 \\
\hline Antenatal care & $29(11.1)$ & 66 (14.9) & 11.695 & 1 & 0.01 \\
\hline Surgical operations & $21(8.0)$ & $8(1.8)$ & 3.737 & 1 & 0.02 \\
\hline Pharmacy/Sales of drugs & $17(6.5)$ & $43(9.8)$ & 11.803 & 1 & 0.01 \\
\hline \multicolumn{6}{|l|}{ Knowledge rating } \\
\hline Good (7-9) & $25(10.0)$ & $28(11.2)$ & & & \\
\hline Fair (4-6) & $183(73.2)$ & $185(74.0)$ & & & \\
\hline Poor (0-3) & $42(16.8)$ & $37(14.8)$ & 0.497 & 2 & 0.779 \\
\hline Mean Knowledge score & $t=0.508$ & & & & 0.612 \\
\hline
\end{tabular}

Table 3 shows the utilization of health facilities, among urban respondents' utilization, were $178(71.2 \%)$ compared with the rural communities $223(89.2 \%)(z-$ Score $=27.93)$. This was found to be statistically significant ( $p$-value $=0.01)$. However, $145(81.5 \%)$ of urban respondents had made 1-2 visits to the health facility in the community in the last 1 month compared with 
$159(71.3 \%)$ among the rural respondents $\left(X^{2}=\right.$ $13.298, p$-value $=0.04)$. About $139(31.5 \%)$ of rural respondents had utilized outpatient services as against $98(37.5 \%)$ of urban respondents. A higher proportion of respondents in the rural communities 106(24.0\%) utilized delivery services compared to urban respondents of $36(13.8 \%)$. The uptake of immunization and family planning activities was higher among urban respondents $60(23.0 \%)$ compared to the rural respondents $84(19.0 \%)$. This was also found to be statistically significant $(p$-value $=$ 0.01).
Furthermore, in table 3 reasons for using health facilities again were presented, such as friendliness of health care workers $78(34.1 \%)$ in the rural and 63(32.9\%) in the urban. Availability of drugs was also a major reason for visiting facility again $54(28.3 \%)$ in urban and $42(18.3 \%)$ in the rural. This finding was statistically significant $(p$-value $=0.02)$. In addition, waiting time at the health facilities was found to be a better determinant of reasons for using health facilities with a mean value of $z$-score $=1.408$; $p$ value $=<0.01$.

Table 3: Respondent's utilization of healthcare facilities among rural and urban communities.

\begin{tabular}{|c|c|c|c|c|c|}
\hline Variables & Urban (\%) & Rural (\%) & $\chi^{2}$ & df & p-value \\
\hline Ever used health care facility & $n=250$ & $n=250$ & & & \\
\hline Yes & $178(71.2)$ & $223(89.2)$ & & & \\
\hline No & $72(28.8)$ & $27(10.8)$ & & & \\
\hline Mean \pm SD & $0.768 \pm 0.54$ & $0.960 \pm 0.96$ & & & \\
\hline Current Use in Last 1 Month & $n=178$ & $n=223$ & & & \\
\hline Nil & $14(7.9)$ & $17(7.6)$ & & & \\
\hline $1-2$ & $145(81.5)$ & 159 (71.3) & & & \\
\hline $3-4$ & $19(10.6)$ & $34(15.3)$ & & & \\
\hline 5 and above & $0(0)$ & $13(5.8)$ & & & \\
\hline Mean No. of Visit & $1.44 \pm 0.38$ & $1.58 \pm 0.35$ & & & \\
\hline Health services utilized (ever used) & $n=261 * *$ & $n=442^{* *}$ & & & \\
\hline Outpatient treatment & $98(37.5)$ & $139(31.5)$ & 1.389 & 1 & 0.24 \\
\hline Delivery & $36(13.8)$ & $106(24.0)$ & 48.194 & 1 & 0.01 \\
\hline Immunization/Family planning services & $60(23.0)$ & $84(19.0)$ & 5.618 & 1 & 0.02 \\
\hline Antenatal care & $31(11.9)$ & $62(14.0)$ & 12.695 & 1 & 0.01 \\
\hline Surgical operations & $19(7.3)$ & $8(1.8)$ & 4.737 & 1 & 0.03 \\
\hline Pharmacy/Sales of drugs & $17(6.5)$ & $43(9.7)$ & 12.803 & 1 & 0.01 \\
\hline Reasons for using health facility(ever used) & $n=193$ & $n=229$ & & & \\
\hline Friendliness of health workers & $63(32.6)$ & $78(34.1)$ & 5.411 & 1 & 0.02 \\
\hline Availability of drugs & $54(28.1)$ & 42 (18.3) & 5.826 & 1 & 0.02 \\
\hline Waiting time & $7(3.6)$ & $24(10.5)$ & 23.601 & 1 & 0.01 \\
\hline Proximity to residence & $45(23.3)$ & $49(21.4)$ & 2.274 & 1 & 0.03 \\
\hline Cheap and affordable & $24(12.4)$ & $36(15.7)$ & 10.163 & 1 & 0.01 \\
\hline
\end{tabular}

${ }^{* *}$ Multiple Responses

In table 4, most of the respondents in the rural community $237(94.8 \%)$ attested to having geographical accessibility to the health facility in their community compared with $201(80.4 \%$ ) with similar accessibility in urban communities $\left(x^{2}=\right.$ 23.866, $p$-value $=0.01$ ). More than half of the rural $126(53.2 \%)$ and urban $117(58.2 \%)$ respondents lived within $<5.0 \mathrm{~km}$ distance from the health facility while a higher proportion of rural respondents $30(12.6 \%)$ traveled $>10 \mathrm{~km}$ distance before accessing modern health care compared to their urban counterpart $18(9.0 \%)$. The mean distance travel by rural respondents was $4.813 \pm 2.1 \mathrm{~km}$ which was higher compared to $4.382 \pm 1.2 \mathrm{~km}$ traveled by the urban respondents.
The views of some of the urban FGD participants corroborate the findings in the quantitative study, some of the responses were that" They do lots of work in the health center especially the government own, for instance, our women deliver there, we the men also go there for treatment anytime we are sick". A similar opinion was expressed by the rural FGD participants on the effect of distance and health care utilization by the community members" I stay in a very distant place but I still make effort to go to the hospital because health is wealth, so I take "Okada" to and from or sometimes trek if time is on my side. Another participant commented, "There are some far away villages that use this health facility 
(PHC) for some of them they come here by commuter buses or private vehicle especially people who stay in Oke-Oyi".

The cost was also a significant factor in access to care, in this study $202(80.8 \%)$ of urban respondents believed that cost of care was expensive compared to $58(23.2 \%)$ of rural respondents who believed the cost of care was expensive. A greater proportion 136 (54.4\%) of rural respondents believed that care was moderate compared to $29(11.6 \%)$ of urban counterparts who said costs were moderate. The mean cost of indirect care i.e., cost of cards $(265 \pm 29.7$ naira) and transportation $(279 \pm 38.4$ naira) were higher among urban respondents compared with the cost for cards $(154 \pm 17.9$ naira) and transportation (108 \pm 19.9 naira) among rural respondents, these were statistically significant ( $p$-value $=0.01)$. The direct cost of care contrast sharply with indirect cost, rural respondents paid a far higher amount $(1,320 \pm 141.9$ naira $)$ compared to the urban respondents $(750 \pm 90.8$ naira) and were also statistically significant ( $p$ value $=0.01$ ).

Table 4: Geographical accessibility/distance Cost of accessing care among rural and urban

\begin{tabular}{|c|c|c|c|c|c|}
\hline Variables & Urban (\%) & Rural (\%) & $\chi^{2}$ & df & p-value \\
\hline \multicolumn{6}{|l|}{ Geographical accessibility } \\
\hline & $\mathrm{n}=\mathbf{2 5 0}$ & $\mathrm{n}=\mathbf{2 5 0}$ & & & \\
\hline Yes & $201(80.4)$ & $237(94.8)$ & & & \\
\hline No & $49(19.6)$ & $13(5.2)$ & 23.866 & 1 & 0.01 \\
\hline \multicolumn{6}{|l|}{ Distance to the health facility } \\
\hline & $\mathrm{n}=201^{* *}$ & $\mathbf{n}=237^{* *}$ & & & \\
\hline$<5.0 \mathrm{~km}$ & $117(58.2)$ & $126(53.2)$ & & & \\
\hline $5.0-10.0 \mathrm{~km}$ & $66(32.8)$ & $81(34.2)$ & & & \\
\hline$>10.0 \mathrm{~km}$ & $18(9.0)$ & $30(12.6)$ & & & \\
\hline Mean Distance & $4.382 \pm 1.20$ & $4.814 \pm 2.1$ & & & \\
\hline Cost of Health Services & $n=250$ & $n=250$ & & & \\
\hline Expensive & $202(80.8)$ & $58(23.2)$ & & & \\
\hline Moderate & $29(11.6)$ & $136(54.4)$ & & & \\
\hline Cheap & $19(7.6)$ & $56(22.4)$ & 85.606 & 2 & 0.01 \\
\hline Indirect cost & Mean \pm SD (\#) & Mean \pm SD (\#) & t-test & & \\
\hline Cost of card & $265 \pm 29.7$ & $154 \pm 17.9$ & 36.961 & & 0.01 \\
\hline Cost of Transportation & $279 \pm 38.4$ & $108 \pm 19.9$ & 47.002 & & 0.01 \\
\hline Direct cost & Mean \pm SD (\#) & Mean \pm SD (\#) & & & \\
\hline Overall cost of care & $750 \pm 90.8$ & $1,320 \pm 141.9$ & 32.356 & & 0.01 \\
\hline
\end{tabular}

Table 5- shows the predictors of utilization of health services, friendliness of health care workers, availability of drugs, the proximity of residence, and cheap and affordable services were identified as factors statistically significant at $p$-value $<0.05$ and were responsible for the utilization of health care facilities among urban respondents. Of all the factors it was, however, observed that waiting time was the strongest of the predictors (OR-1.012, Cl-0.192-5.337) identified among urban respondents with an odds ratio of 1.012 , though not statistically significant $(p$-value $=0.989)$. In addition, the availability of drugs was the strongest of the predictors (OR1.696, Cl-0.486-5.912) identified among rural respondents with an odds ratio of 1.696 this was also not statistically significant $(p$-value $=0.407)$.

Table 5: Predictors of Utilization of Health Care Services by Urban and rural communities

\begin{tabular}{lccc}
\hline Variables & Odds ratio & $\mathbf{9 5} \%$ C. I & p-value \\
\hline Urban Community & & & \\
Others (RC) & & & \\
Friendliness of health care workers & 0.750 & $0.406-1.387$ & 0.359 \\
Availability of drugs & 0.683 & $0.360-1.297$ & 0.243 \\
Prompt attention & 1.012 & $0.192-5.337$ & $0.989^{*}$ \\
Proximity of residence & 0.879 & $0.425-1.816$ & 0.727 \\
Cheap and affordable & 0.980 & $0.388-2.475$ & 0.967 \\
Rural Community & & &
\end{tabular}




\begin{tabular}{|c|c|c|c|}
\hline \multicolumn{4}{|l|}{ Others (RC) } \\
\hline Friendliness of health care workers & 0.702 & $0.315-1.564$ & 0.387 \\
\hline Availability of drugs & 1.696 & $0.486-5.912$ & $0.407^{\circ}$ \\
\hline Prompt attention & 0.372 & $0.155-0.896$ & 0.027 \\
\hline Proximity of residence (RC) & 0.736 & $0.314-1.728$ & 0.482 \\
\hline Cheap and affordable & 0.549 & $0.232-1.298$ & 0.172 \\
\hline
\end{tabular}

\section{Discussion}

This study found most respondents had secondary education, although there were more tertiary-educated respondents in the urban than the rural community. Education is good as a foundation to understanding health demands and seeking health when the need arises both in the rural and urban communities. The importance of education and knowledge development was again emphasized by a study conducted among rural Pakistanis (25) on health-seeking behavior and health service utilization, reasonably the high proportion of respondents with secondary education in this study is a positive influence on health-seeking behavior both among the rural and urban communities. The significance of improving knowledge to ensure adequate health care utilization was also demonstrated in the Akure study (18), the study found that to improve healthcare utilization there must be adequate knowledge by community people. Most of the respondents in both the rural and urban communities had a fair knowledge of available health facilities and the services they provided. This finding is good as it would encourage participation and improve healthcare utilization by both rural and urban communities (24).

This study found the proportion of healthcare utilization (ever used) among the urban respondents to be slightly lower than what was observed among the rural respondents, this contradicted the findings in Cross-River (10), Ibadan (26), and Kogi (27) states all in Nigeria, where lower utilization was reported among rural inhabitant compared with their urban counterpart. A similar study in Ekiti (23) revealed that rural women were less likely to use antenatal care than urban women. Two important factors played role in the findings in our study, in the first instance a tertiary health center, the university teaching hospital is located close to one of the selected rural communities, and therefore, it was easy for the rural inhabitant to access the health facility. However, there is an increasing awareness of the importance of health care utilization among these rural community members and it is a confirmation of the need to provide health facilities close to rural communities $(28,29,30)$.

Utilization in the preceding one month before the study showed that most respondents in the rural community had visited health facilities in their community between 1-2 times more than their urban counterparts. The findings in this study were supported by the result of an appraisal of factors preventing utilization of health services among the rural population in Owerri, South-East, Nigeria (28). The study showed that health care providers in the rural areas were not only a few but have been deprived of necessary tools for service delivery, as a result, rural health care is at risk; the consequences to healthcare delivery were identified in a southern Nigerian study (31) as inadequate health personnel, diagnostic services available in some urban centers were also found to be non-existent in rural areas by Siraff T. in Ashanti region of Ghana (32).

From the foregoing, this study showed that if facilities in the rural communities had enough personnel and resources, rural dwellers would use healthcare services as much as their urban counterparts. Apart from surgical services which were better utilized by the urban respondents more than the rural counterpart, all other services were more utilized by rural dwellers as indicated in this study. This finding contradicts some publications which predicted more service utilization among the urban respondents $(10,23$, $26,27)$. The higher utilization of surgical services seen among the urban community was due to the availability of necessary equipment and personnel to carry out surgical procedures as against rural facilities where such might be lacking. However, data from current usage, showed that rural communities would use all services if personnel and equipment were made available $(23,27)$.

The factors identified in this study that influence healthcare utilization were either health-related or non-health-related factors. The non-healthrelated factors were geographical accessibility. The study showed that in terms of distance, the clinics were accessible as most of the participants 
lived within $5 \mathrm{~km}$ of such facility. Also, in this study, a substantial proportion of the rural respondents affirmed that they were geographically accessible to health facilities within their community. Most of the rural respondents claimed to visit health facilities by trekking within $<5 \mathrm{~km}$ distance to their houses. The implication of this finding to healthcare utilization is that if the government provides health facilities within $<5 \mathrm{~km}$ distance it would go a long way in improving healthcare utilization.

In the same vein, a study in Ekiti (23), Ghana (32), and South Africa (33) revealed that distance was a stronger predictor of attendance of antenatal care in a study on urban-rural differentials of antenatal care utilization. This discovery, therefore, reinforced the need to ensure the availability of health facilities within proximity especially in the rural community where means of transportation could be a major problem to health care utilization.

Health service-related factors affecting healthcare utilization in this study were the friendliness of health personnel, availability of drugs, waiting time, and proximity of health facilities to place of residence. This study found that waiting time was a strong determinant of healthcare utilization among urban respondents, compared with the availability of drugs in the health facilities which was the strongest predictor among rural respondents.

A study in Ibadan (26) found that good services, facilities near to residence, waiting time, drugs were available, services were available, health workers were competent, services were accessible and drugs were affordable as factors that determined utilization of primary health care among urban respondents. Although the Ibadan study (26) does not subject their findings to logistic regression, a higher proportion of the urban respondents believed that good service and facilities close to their houses were the most favored determinants of utilization. The overall implication of this finding was that to ensure adequate utilization of modern health facilities among the rural community members there must be access to subsidized and quality drugs in the PHC facilities and the need for government to strengthen drug revolving scheme to ensure availability of drugs.

This study found a mean earning among urban respondents to be almost twice as high as their rural counterparts, this is not uncommon as urban respondents were mostly civil servants while their rural populace was mostly peasant farmers who earn from the proceed of farm produce. Despite low earning among the rural community members, a study (30) showed that they pay disproportionately more to access healthcare compared with their urban counterparts. This might not be unconnected with a higher mean cost of direct and indirect health expenditure in the rural compared with the findings among the urban respondents. Economic power to utilize health services was not so very different globally, for instance, the World Health Organization report estimated 76 percent of Total Health Expenditure in India were out of pocket which directly affects health care utilization especially among the rural poor and urban living in slums scattered across the country (29).

The cost of health care services has been identified as a major factor in utilization. The influence of cost on health facility utilization was reported in a study in South-west, Nigeria which concluded that cost/payment for services was more likely to predict the use of public health facilities than the usual health care providers (34). This study found a mean cost of assessing health services among urban respondents to be lower compared with the cost of assessing health care in the rural community.

The findings in this study were similar to that of a related study in Afon and Ajasse areas of Kwara State, North-central, Nigeria (35) which revealed that the poor spend disproportionately more than the "rich" on health care. The poorest quintile in the study spends on an average higher proportion of their annual per capita consumption on out-ofpocket for health care and transportation to health facilities as compared with the richest quintile that spends a lower proportion of their annual per capita consumption out-of-pocket and on transportation for health care (35). The implication of this high rate of out-of-pocket payment could have been responsible for alternative health-seeking behaviors such as patronage of herbalists and self-medication as discovered among the FGD rural participants who lamented that" treatment in the hospital is more expensive than traditional setting that is why some people prefer to go to them."

A study on crises and challenges in the Nigerian health sector emphasized the significant impact other sectors played in the need to provide equitable health and sustainable development in a way to maximally advance public health (36). These were captured among the opinion of respondents in this study on the trend of health system-related problems facing health care facilities in rural and urban communities. Some of the problems identified in this study facing health 
service delivery in both the rural and urban communities include long travel distances, poor road network, lack of drugs especially in public health facilities, obsolete equipment, lack of staff, and expensive service delivery. A study in Ilorin, North-central, Nigeria identified similar factors as a hindrance to access and utilization of approved health facilities in related settings (37).

\section{Conclusion}

This study demonstrated a higher proportion of rural respondents had ever used health facilities compared to urban respondents. It also showed that knowledge is a vital requisite for health utilization, this study identified several predictors of healthcare utilization among the rural and urban respondents among which were the friendliness of health care workers, availability of drugs, waiting time, and proximity of residence to the health facility with cheap and affordable services. Information on healthcare utilization has an important policy implication in health systems development.

Sequel to the findings from this study, the following recommendation was therefore made to improve healthcare utilization among rural and urban communities:

1. There must be increase awareness among the people of the need to be healthy; this can also be achieved through enhancing the educational status of especially women in rural communities.

2. Training and retraining of health personnel on friendliness and putting up good attitude to encourage hospital visits among clients.

3. Also training and retraining of healthcare personnel on triaging of patients especially in urban clinics and hospitals where patient's turnout could often time be overwhelming.

4. The government at the state and local governments should reduce drug costs through subsidies and making essential drugs available. The availability of drugs in this study has been shown to improve hospital visits.

5. The access road is very important to ease of accessing healthcare services, government should continue to improve access to health facility especially in the rural communities.

\section{Declarations}

\section{Ethics Consideration}

Ethical approval for the study was obtained from the Ethical Review Committee, University of Ilorin Teaching Hospital with protocol number ERC PIN/2014/02/0157. Permission was sought from the heads of the selected wards and the Chairman of Ilorin East Local Government Area. The purpose and benefits of the study were explained accordingly. Informed written consent was also obtained (signature or thumbprint) from the study subjects before conducting the interview. Confidentiality of information provided was maintained. No injuries or adverse events were expected by participating in this study, and as such, no compensation was required.

\section{Consent for publication}

The authors hereby give consent for the publication of this work under the Creative Commons CC Attribution. Non-commercial 4.0 license.

\section{Availability of data and materials}

All data generated or analyzed in this study are included in this article and are available at any request.

\section{Competing interests}

The authors declare that they have no competing interests

\section{Funding}

None

Authors' contributions

Study design: AAK

Data collection: AA

Data analysis: AAK, OOY

Study supervision: ATM, OGK

Manuscript writing: AAK, OOY

Critical review for important intellectual content: AAK, OOY, AA, ATM, OGK

\section{Acknowledgments}

We express our thanks to all individuals who participated in the study: respondents, data collectors, and administrative officials.

\section{References}

1. World Health Organization. World Health Report. Bulletin of the world health organization. December 2014; Volume 82, Number 12: 891-970

2. Federal Ministry of Health. The National Health Policy and Strategy to Achieve Health for All Nigerians 2015: 9-21

3. AbduIRaheem IS, Oladipo AR, Amodu MO. Primary Health Care Services in Nigeria: Critical Issues and Strategies for enhancing the use by the Rural Communities. JPHE; 
2012 January; 4; 1: 5-13ref.22 https://doi.org/10.5897/iphe11.133

4. Adeyemo DO. Local government and health care delivery in Nigeria: a case study. Journal of Human Ecology. 2005 Oct 1;18(2):149-60.

5. Federal Ministry of Health. Primary Health Care in Nigeria: 42 years after Alma Ata Declaration. Syndani Initiative for International Development. September 9, 2020: 99-108

6. National Population Commission (NPC) [Nigeria] and ICF. 2019 Nigeria Demographic and Health Survey 2018. Abuja, Nigeria, and Rockville, Maryland, USA: NPC and ICF.

7. National Demographic and Health Survey. Abuja. National Population Commission. 2014.

8. UNAIDS/ Nigeria National HIVIAIDS council. Monitoring and Evaluating Operations manual August 2012: Abuja.

9. Adesiji GB, Dada SO, Komolafe SE. problems faced by rural people in accessing health care facilities in Akure North and Akure South local government areas of Ondo State, Nigeria. J Appl Sci Res. 2012;8(4):2260-6.

10. Ugal DB, Ushie BA, Ushie M, Ingwu J. Utilization of Facilities and Maternal Health out care among urban dwellers of Obudu and Ogoja Local Government Area of Cross River State, Nigeria. Afro Asian Journal of Social Sciences. https://doi.org/10.2139/ssrn.1513974

11. Federal Ministry of Health. National Human Resources for Health Strategic Plan 2008 to 2012. Abuja, Nigeria. 2013 April. http://www.Nigeria-HRHstrategicplan-20082012 Accessed on 16th April 2020.

12. Sule SS, ljadunola KT, Onayade AA, Fatusi $A O$, Soetan RO, Connell FA. Utilization of primary health care facilities: lessons from a rural community in southwest Nigeria. Nigerian journal of medicine. $2008 \mathrm{Apr}$ 22;17(1):98-106. https://doi.org/10.4314/nim.v17i1.37366

13. Abubakar F. The Trend/Pattern of Membership Registration at the Savelugu/Nanton District Mutual Health Insurance Scheme in Northern region. PhD Thesis. Kwame Nkrumah University of Science and Technology Ghana; 2012.3; 180. http://hdl.handle.net/123456789/3868

14. Adewoye KR, Musa IO, Atoyebi OA, Babatunde OA. Knowledge and utilization of antenatal care services by women of childbearing age in Ilorin-East local government area, North Central Nigeria. International Journal of Science and Technology. 2013 Mar;3(3):17-22.

15. Akande TM. Breaking the Barriers to Effective Health Care Delivery. A Paper Presentation at the 2013, Annual General Meeting of Nigeria Medical Association (Kwara State, branch); Kwara Hotels, Ilorin. 2013. 5; 1-7.

16. Riman HB, Akpan ES. Healthcare financing and health outcomes in Nigeria: A state-level study using multivariate analysis. International Journal of Humanities and Social Science 2012; 2(15):296-309.

17. World Health Organization. Urbanization and health: health equity and vulnerable populations: case studies from the Eastern Mediterranean Region. 2010.

18. Kwara State Government. Profiles of Ilorin East Local Government Area. Ilorin, Kwara State. KWSG. 2013 February. http//www.kwaraadv.asp files.ng. Accessed14th February 2020.

19. Kwara State Government. Information document on Health care services in Ilorin East Local Government area. Ilorin, Kwara State. Sourced through the Office of the PRO Ilorin East Local Government Area. 2020.

20. Abdur-Rahman LO, Musa OI, Oshagbemi GK. Community-based study of circumcision practices in Nigeria. Annals of Tropical Medicine and Public Health. 2012 May 1;5(3):231. https://doi.org/10.4103/1755$\underline{6783.98625}$

21. National Population Commission. National Development Plan. Abuja. National Population Commission. 2008.

22. Jekel JF, Katz DL, Elmor JG, Wild DMG. Sample Size, Randomization, and Probability Theory. In: Epidemiology, Biostatistics and Preventive Medicine. 3rd ed. Philadelphia: Saunders Elsevier: 20013. 197-202. eBook ISBN: 9781455706563

23. Babalola BI. Determinants of urban-rural differentials of antenatal care utilization in Nigeria. African Population Studies. 2014 Sep 22;28(3):1263-73. https://doi.org/10.11564/0-0-614

24. The Federal Republic of Nigeria. Nigeria Demographic and Health Survey 2016. National Population Commission Abuja.

25. Shaikh BT, Hatcher J. Health seeking behaviour and health service utilization in Pakistan: challenging the policymakers. Journal of public health. 2005 Mar 
1;27(1):49-54. https://doi.org/10.1093/pubmed/fdh207

26. Asuzu MC, Adebayo AM. Utilisation of a community-based health facility in a lowincome urban community in Ibadan, Nigeria. African Journal of Primary Health Care and Family Medicine. 2015 Jan 1;7(1):1-8. https://doi.org/10.4102/phcfm.v7i1.735

27. Awoyemi TT, Obayelu OA, Opaluwa HI. Effect of distance on utilization of health care services in rural Kogi State, Nigeria. Journal of Human Ecology. 2011 Jul 1;35(1):1-9. https://doi.org/10.1080/09709274.2011.1190 $\underline{6385}$

28. Azuh D. Knowledge of socio-demographic Factors Influencing Health Programme Usage by Pregnant Mothers in Nigeria: Implications for Policy Action. 2017:3(9):1043-1050. https://doi.org/10.18769/ijasos.370661

29. Navaneetham K, Dharmalingam A. Utilization of maternal health care services in Southern India. Social science \& medicine. 2002 Nov 1;55(10):1849-69.

https://doi.org/10.1016/s02779536(01)00313-6

30. Global Health University. Urban versus Rural Health. Unite for sight. April 2013. Available at http://www.uniteforsight.org. Accessed on 10th, September 2021.

31. Uchendu OC, Ilesanmi OS, Olumide AE. Factors influencing the choice of health care providing facility among workers in a local government secretariat in southwestern Nigeria. Annals of Ibadan postgraduate medicine. 2013;11(2):87-95.

32. Siraff T. An Assessment of Factors Influencing Utilization of Antenatal Care Services in Atwima Nwabiagya District of Ashanti Region. A Thesis. Field Survey 2008: 1-27.

33. Nteta TP, Mokgatle-Nthabu M, Oguntibeju OO. Utilization of the primary health care services in the Tshwane Region of Gauteng Province, South Africa. PloS one. 2010 Nov 9;5(11):e13909. https://doi.org/10.1371/journal.pone.001390 $\underline{9}$

34. Iyalomhe GB, Iyalomhe SI. Health-seeking behavior of rural dwellers in southern Nigeria: implications for healthcare professionals. International journal of tropical disease \& health. $2012 \quad$ Mar 4:62-71. https://doi.org/10.9734/ijtdh/2012/973

35. Janssens W, Goedecke J, De Bree GJ, Aderibigbe SA, Akande TM, Mesnard A. The financial burden of non-communicable chronic diseases in rural Nigeria: wealth and gender heterogeneity in health care utilization and health expenditures. PLoS One. 2016 Nov 10;11(11):e0166121. https://doi.org/10.1371/journal.pone.016612 1

36. Osibogun A. Crises and challenges in the Nigerian health sector. Journal of Community Medicine and Primary Health Care. 2004;16(2):1-7. https://doi.org/10.4314/jcmphc.v16i2.32406

37. Abdulraheem BI, Olapipo AR, Amodu MO. Primary health care services in Nigeria: Critical issues and strategies for enhancing the use by the rural communities. Journal of public health and epidemiology. 2012 Jan 31;4(1):5-13. https://doi.org/10.5897/jphe11.133 